\title{
IGF2 related non-islet cell tumour hypoglycaemia in a patient with hepatic sarcoma
}

\section{Background}

69 year old male

PMHx: epigastric hernia and T2DM

-Initially presented to GP with epigastric and right upper quadrant pain.

- Primary results showed deranged LFTs and CT imaging / biopsy confirmed an inoperable hepatic sarcoma

-A few months later presents to the emergency department with hypoglycaemia and whipple's triad

\section{Investigations and results}

Glucose: $2 \mathrm{mmol} / \mathrm{L}$

Insulin: $<1.01 \mathrm{U} / \mathrm{L}$

C-peptide: $<0.1 \mathrm{nmol} / \mathrm{L}$

Short synacthen test: normal

IGF2:IGF1 ratio $14.7 \rightarrow$ overproduction of "Big IGF2"

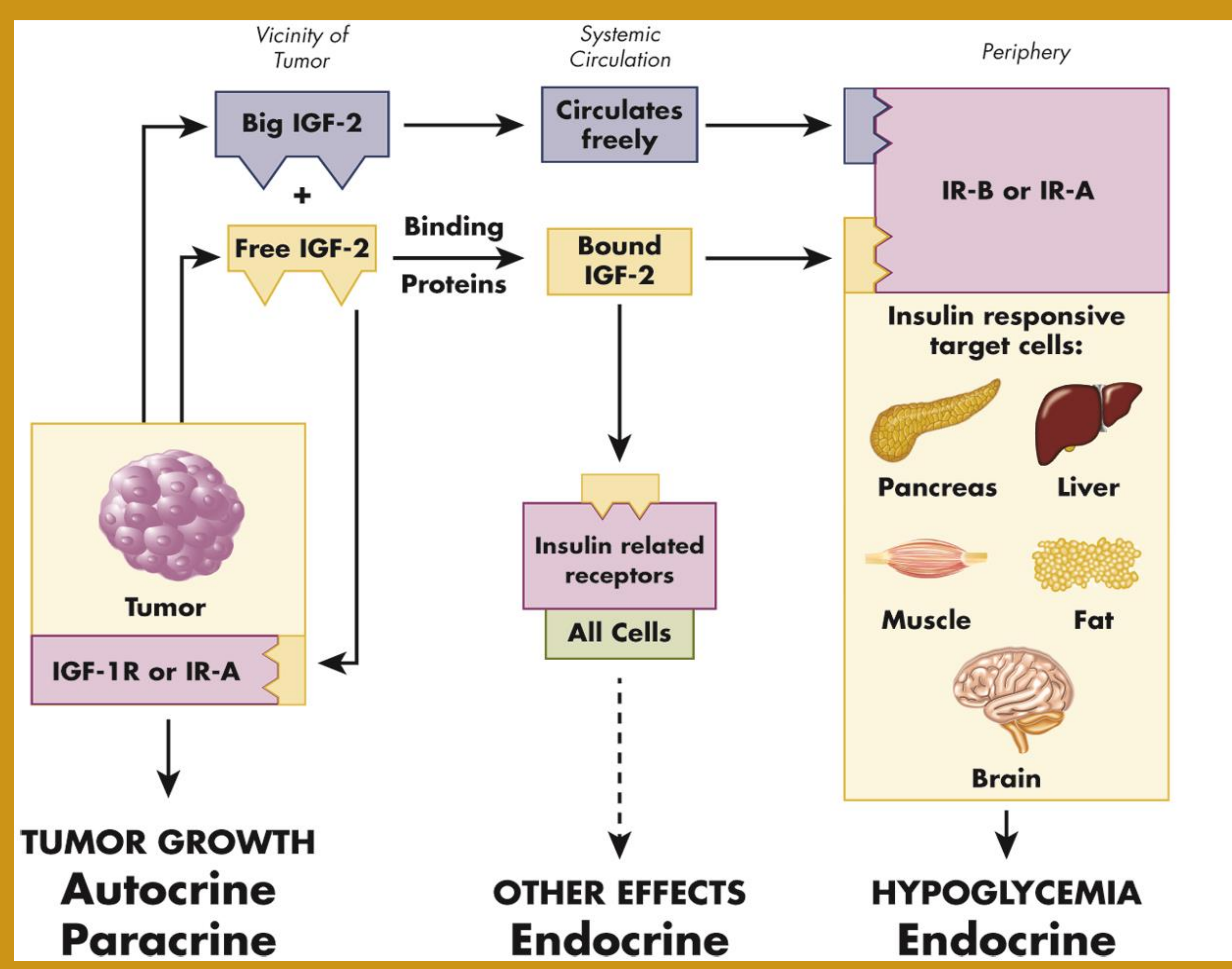

Figure 1: Effects of "big IGF-2" on target cells ${ }^{1}$

\section{References}

1 Y.Dynkevich, K.Rother, I.Whitford, et al; 2013.Tumors, IGF-2, and Hypoglycemia: Insights From the Clinic, the Laboratory, and the Historical Archive, Endocrine Reviews. 34;6:798-826.

2 J. de Groot, B. Rikhof, J. van Doorn, et al; 2007. Non-islet cell tumourinduced hypoglycaemia: a review of the literature including two new cases, Endocrine-Related Cancer, 14;4:979-993.

\section{Conclusion}

-Results confirm a diagnosis of non-islet cell tumour hypoglycaemia

-IGF-2 binds to target cells like insulin and promotes hypoglycaemia

-There is an overall increase in "big IGF2" and IGF2 in binary complexes; which are more permeable and lead to greater bioavailability further contributing to hypoglycaemia

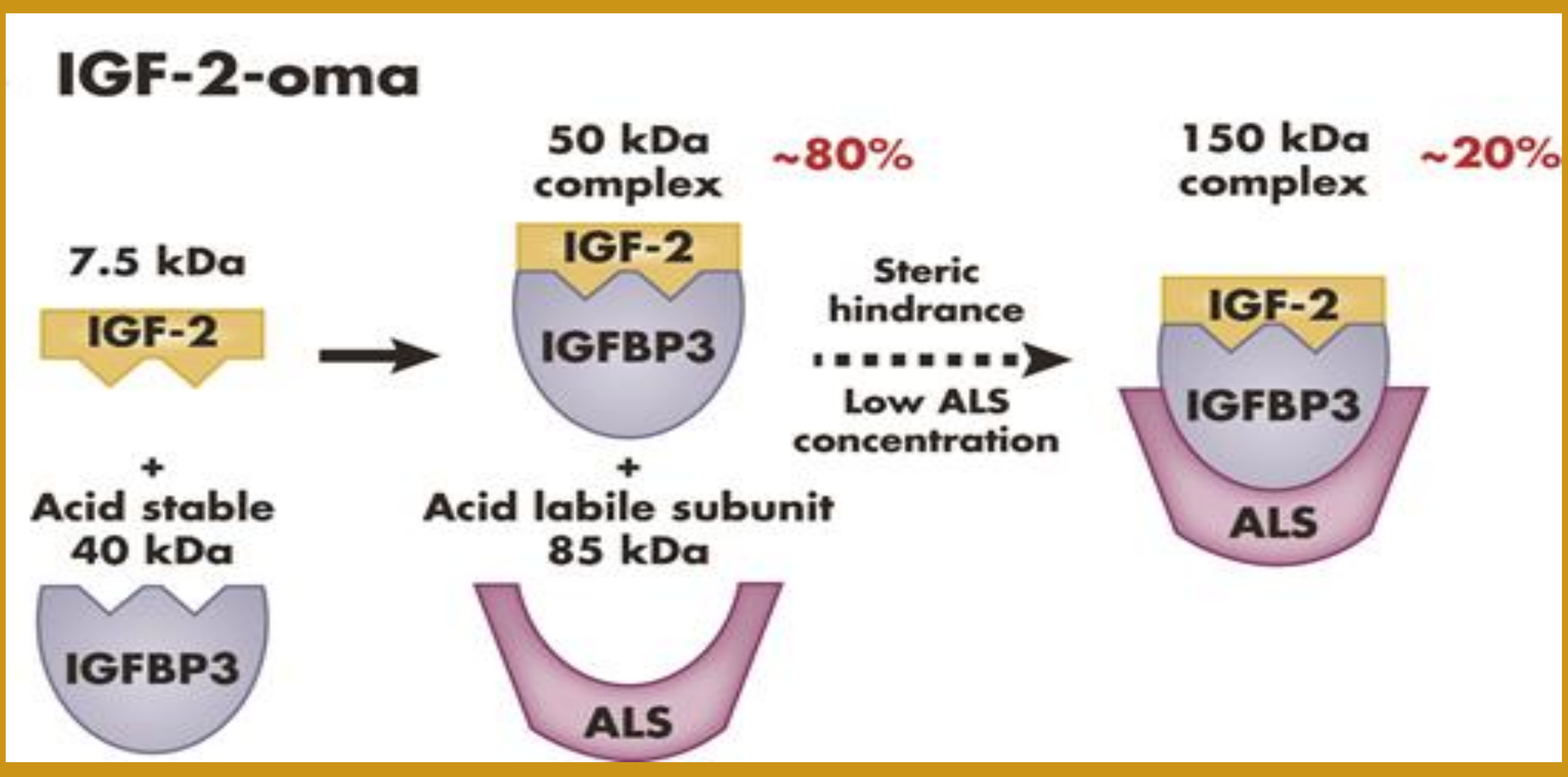

Figure 2: IGF-2 produced by tumours has Increased permeability and bioavailability to tissues. Normally, $80 \%$ of IGF-2 is bound in the ternary complex, in IGF-2 secreting tumours, $80 \%$ is bound in the binary complex.

\section{Discussion}

Although rare, the exact incidence of non-islet cell tumours causing hypoglycaemia is unknown and they are often diagnosed late, with hypoglycaemia as the presenting symptom in many cases. ${ }^{2}$

Treatment options are limited, however if surgical resection is possible, hypoglycaemia can be fully resolved. Unfortunately for this patient, the tumour was inoperable due to size and location.

Management consisted of steroids at supraphysiological dose and regular carbohydrate intake. Despite this, he required multiple hospital admissions for hypoglycaemia.

Other treatment options include recombinant growth hormone, which increases gluconeogenesis, ALS and IGFBP3; however this would also increase tumour growth in this case. Glucagon and diazoxide have also been used, although evidence is limited. 